\title{
INTERVALO DE TEMPO PARA SEMEADURA DE MILHO PÓS-DESSECAÇÃO DA COBERTURA DE AVEIA-PRETA COM HERBICIDAS
}

\author{
ESTABLISHMENT OF CORN SEEDING TIME INTERVAL \\ AFTER DESICCATION OF OATS WITH HERBICIDES
}

\author{
Rodrigo Neves ${ }^{1}$ Nilson Gilberto Fleck ${ }^{2}$ Ribas Antonio Vidal ${ }^{3}$
}

RESUMO

Com o objetivo de investigar o intervalo de tempo para semeadura de milho cultivado em sucessão à aveia-preta dessecada com herbicidas não-seletivos, realizou-se experimento fatorial na Estação Experimental Agronômica da UFRGS, em Eldorado do Sul, RS, em 1997/98. Um fator constou de quatro épocas de dessecação da aveia-preta (13, 9, 5 e 1 dia antes da semeadura do milho). $O$ outro fator consistiu de quatro sistemas utilizados em pré-semeadura da cultura (aplicação do herbicida glyphosate "540gha -1 $^{-1}$.a." sobre plantas de aveia-preta ou sobre o solo sem sua presença; aplicação do herbicida paraquat

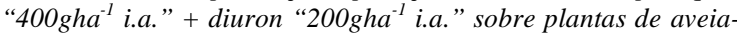
preta; e testemunha cuja semeadura do milho ocorreu na ausência de aveia-preta e de aplicação de herbicidas). Não se constatou interação entre os fatores testados. Com relação aos sistemas de pré-semeadura do milho, observou-se aumento na estatura acompanhado de decréscimo na massa seca de planta, tanto aos 20 como aos 40 dias após a emergência, quando o milho foi semeado na presença de resteva de aveia-preta em relação aquele semeado na sua ausência. Para intervalos de semeadura do milho pós-dessecação da aveia-preta, não ocorreram diferenças significativas tanto no desenvolvimento inicial das plantas, na estatura final, quanto no rendimento de grãos.

Palavras-chave: Glyphosate, paraquat, Avena strigosa S., semeadura direta.

\section{SUMMARY}

With the purpose of evaluating time intervals for corn seeding after forage oats desiccation with non-selective herbicides, it was conducted a factorial trial in Agronomic Experimental Station of UFRGS, in Eldorado do Sul, RS, Brazil, in the 1997/98 growing season. One factor consisted of four times of oats desiccation (13, 9, 5 and 1 day before corn seeding). The

\begin{abstract}
other factor was four corn pre-seeding systems (glyphosate "540gha-1 e.a." herbicide applied on oat plants or on soil surface without oats; paraquat "400gha ${ }^{-1}$ i.a." + diuron "200gha i.a." $^{-1}$ herbicide applied on oat plants; and a control in which corn seeding occurred in absence of oats and of herbicide use). There were no significant interactions between factors tested. In relation to corn pre-seeding systems, it was observed an increase in plant height, followed by decrease in plant dry matter, as determined 20 and 40 days after emergence, when corn was seeded in the presence of oat straw, in relation to corn seeded in its absence. For corn seeding time intervals after oat desiccation there were no significant differences for initial growth of corn plants and either in corn final height or grain yield.
\end{abstract}

Key words: Glyphosate, paraquat, Avena strigosa S., no-till.

\section{INTRODUÇÃO}

Atualmente, no Estado do Rio Grande do Sul, a aveia-preta (Avena strigosa S.) e a aveiabranca (Avena sativa L.) são as principais culturas de inverno utilizadas com os objetivos de cobrir o solo e de fornecer palha ao sistema de semeadura direta. Porém, o acúmulo de resíduos vegetais na superfície do solo acarreta aumentos da atividade biológica e na mineralização do material orgânico e, conseqüentemente, em transformações do Namoniacal. Deve-se considerar que a relação $\mathrm{C} / \mathrm{N}$ destes resíduos vegetais influencia diretamente a taxa de mineralização do nitrogênio pelos microorganismos no solo e a relação oferta/demanda desse pelas culturas (SÁ, 1993).

\footnotetext{
${ }^{1}$ Engenheiro Agrônomo, Mestre, Aluno do Programa de Pós-graduação em Agronomia da Faculdade de Agronomia da UFRGS

${ }^{2}$ Engenheiro Agrônomo, Doutor, Pesquisador Associado, Departamento de Plantas de Lavoura, Faculdade de Agronomia, Universidade Federal do Rio Grande do Sul (UFRGS). Bolsista do CNPq, CP 776, 91501-970, Porto Alegre, RS. Autor para correspondência.

${ }^{3}$ Engenheiro Agrônomo, Doutor, Professor Adjunto do Departamento de Plantas de Lavoura, Faculdade de Agronomia da UFRGS. Bolsista do CNPp.
} 
Materiais com alta relação $\mathrm{C} / \mathrm{N}$, como a palha de cereais, apresentam menores taxas de decomposição (VELLOSO \& ROMAN, 1993), o que resulta em menor produção de nitrogênio (AITA $\boldsymbol{e t}$ al., 1994; TEIXEIRA et al., 1994; DA ROS \& AITA, 1996) e menor rendimento de grãos de milho em relação ao semeado em sucessão a leguminosas (PÖTTKER \& ROMAN, 1994; DA ROS \& AITA, 1996).

Por outro lado, o rendimento de grãos do milho pode ser reduzido quando ele é implantado imediatamente sobre resíduos culturais de espécies de inverno, principalmente de gramíneas (RAIMBAULT et $\boldsymbol{a l}$., 1991; RUEDELL, 1995). Estas reduções são atribuídas, principalmente, ao efeito da alta relação $\mathrm{C} / \mathrm{N}$. A imobilização líquida de nitrogênio poderá ocorrer nos períodos iniciais da decomposição (JENSEN, 1997). Entretanto, a continuidade do processo de decomposição dos resíduos diminui a relação $\mathrm{C} / \mathrm{N}$ no solo, uma vez que o carbono é perdido na forma de $\mathrm{CO}_{2}$ e o nitrogênio é conservado pela formação de massa celular microbiana (VICTORIA et al., 1992).

Neste sentido, a determinação do intervalo de tempo para semeadura do milho após a dessecação de culturas de cobertura do solo representa prática de manejo a ser adotada visando-se à implantação da cultura em época mais favorável para reduzir a competição desta com os microorganismos pelo nitrogênio (RAIMBAULT et al., 1991; RUEDELL, 1995). De acordo com RUEDELL (1995) e RECOMENDAÇÕES... (1997), a eliminação mecânica e/ou química das culturas de inverno, antes da implantação do milho, mais especificamente nos casos da aveia-preta e do azevém, deve ser realizada no mínimo 20 dias antes da semeadura do milho. Evita-se, assim, possíveis efeitos alelopáticos, competição por nitrogênio ou mesmo efeito de resíduos dos herbicidas utilizados na dessecação, conforme enfatizam diversos autores.

Quanto à residualidade no solo dos herbicidas utilizados no manejo químico das coberturas, não seria necessário respeitar o intervalo mencionado. Esse fato deve-se à forte adsorção dos herbicidas glyphosate e paraquat às partículas de argila e de matéria orgânica, o que os torna praticamente inativos no solo (SPRANKLE et al., 1975; RODRIGUES \& ALMEIDA, 1995). Isto foi confirmado por FLECK et al. (1997), os quais constataram que, na ausência de resteva, não houve diferença no crescimento inicial do milho em relação à testemunha quando os herbicidas glyphosate e 2,4-D foram aspergidos diretamente no solo. No entanto, foi necessário aguardar um intervalo de tempo de pelo menos 10 dias entre a aplicação do herbicida e a semeadura, quando a aspersão foi realizada sobre plantas de aveia-preta ou ervilhaca.

Outro fator que assume importância na prática da semeadura direta relaciona-se aos possíveis efeitos alelopáticos depressivos ocasionados pela liberação de aleloquímicos ao meio, a partir da decomposição de resíduos vegetais no solo (ALMEIDA, 1988). Substâncias com ação alelopática, como escopoletina, foram identificadas entre aquelas exudadas por raízes de aveia, as quais foram capazes de inibir o desenvolvimento de plantas de Brassica kaber, azevém e trigo (FAY \& DUKE, 1977; JACOBI, 1997). Da mesma forma, extratos obtidos de plantas de aveia e soja causaram decréscimo de $61 \%$ no comprimento da radícula e em raízes secundárias, bem como redução de $74 \%$ na germinação do milho (MARTIN et al., 1990).

O presente experimento objetivou definir o intervalo de tempo para semeadura do milho cultivado em sucessão à aveia-preta dessecada com os herbicidas glyphosate ou paraquat em sistema de semeadura direta.

\section{MATERIAL E MÉTODOS}

Um experimento foi conduzido a campo, durante o período julho de 1997 a fevereiro de 1998, na Estação Experimental Agronômica (EEA) da Universidade Federal do Rio Grande do Sul (UFRGS), localizada no município de Eldorado do Sul, região fisiográfica da Depressão Central do Rio Grande do Sul e caracterizada por apresentar clima subtropical úmido. O solo do local pertence à unidade de mapeamento São Jerônimo, classificado como Podzólico vermelho-escuro, distrófico (Paleudult) (ESPÍRITO SANTO, 1988).

$\mathrm{Na}$ etapa inicial do experimento foi implantada a cultura da aveia-preta (Avena strigosa S.), na densidade média de 300 plantas $\mathrm{m}^{-2}$, semeada em linhas espaçadas em 0,20m, em 02 de julho de 1997. Aos 35 dias após a emergência das plantas de aveia-preta, efetuou-se sua eliminação via química onde se desejava manter a área em sistema de pousio (solo descoberto). Para tal, utilizou-se o herbicida glyphosate na dose de $540 \operatorname{gha}^{-1}$ e.a. A adubação nitrogenada em cobertura para esta cultura foi aplicada 45 dias após sua emergência, utilizando-se $54 \mathrm{kgha}^{-1}$ de nitrogênio (equivalentes a $120 \mathrm{kgha}^{-1} \mathrm{de}$ uréia).

Para semeadura do milho (Zea mays L.), utilizou-se o híbrido 'XL-212', o qual foi estabelecido na densidade de 70.000 plantas ha $^{-1}$ em espaçamento de $0,7 \mathrm{~m}$ entre fileiras. A semeadura ocorreu no dia 17 de setembro de 1997 e a colheita das espigas no dia 18 de fevereiro de 1998 (145 dias após a 
emergência). A adubação do solo foi realizada juntamente com a operação de semeadura e constou da distribuição de $45 \mathrm{kgha}^{-1}$ de $\mathrm{N}, 120 \mathrm{kgha}^{-1}$ de $\mathrm{P}_{2} \mathrm{O}_{5}$ e $100 \mathrm{kgha}^{-1}$ de $\mathrm{K}_{2} \mathrm{O}$. Em cobertura, utilizou-se adubação com $100 \mathrm{kgha}^{-1}$ de nitrogênio $\left(210 \mathrm{kgha}^{-1} \mathrm{de}\right.$ uréia), que foi parcelada em duas aplicações.

Os tratamentos foram arranjados no delineamento experimental de blocos completamente casualizados, com quatro repetições, dispostos em esquema fatorial. Cada unidade experimental apresentou área de $21 \mathrm{~m}^{2}(6 \mathrm{~m} \times 3,5 \mathrm{~m})$, contendo quatro fileiras de plantas. A fim de simular-se diferentes datas de semeadura do milho pós-dessecação da cobertura vegetal de aveia-preta, realizaram-se, inversamente, aplicações herbicidas em várias épocas. As épocas de dessecação da aveia-preta, utilizadas como um dos fatores, ocorreram aos $13,9,5$ e 1 dia antes da semeadura do milho. O outro fator foi representado por quatro sistemas de pré-semeadura do milho: dessecação com glyphosate [N(fosfometil) glicina], na forma de sal de isopropilamina, na dose de $540 \mathrm{gha}^{-1}$ e.a., aplicado sobre plantas de aveia-preta e também sobre solo descoberto; paraquat (1,1'-dimetil-4,4'bipiridilio), na forma de íon dicloreto, mais diuron [N'-(3,4-diclorofenil)$\mathrm{N}, \mathrm{N}$-dimetiluréia], nas doses de $400 \mathrm{gha}^{-1}$ e $200 \mathrm{gha}^{-1}$ de i.a., acrescidos de Agral (0,1\% v/v); e semeadura do milho na ausência de resteva e de herbicida (testemunha).

Os herbicidas foram aplicados nos dias 4, 8, 12 e 16 de setembro de 1997. Nestas épocas, a aveia-preta produziu média de $6000 \mathrm{kgha}^{-1}$ de matéria seca, variável de 5600 até $6500 \mathrm{kgha}^{-1}$ da primeira para a última aplicação. Para as aspersões utilizou-se pulverizador costal de precisão, operado à pressão constante de $200 \mathrm{kPa}$, empregando-se bicos jato plano, do tipo leque, série 110.03 , os quais propiciaram volume de calda equivalente a $200 \mathrm{lha}^{-1}$.

Os efeitos dos tratamentos foram estimados através das avaliações da estatura e da massa seca do milho, realizadas aos 20 e 40 dias após a emergência (DAE), determinadas em 10 plantas por parcela. Também foram determinados estatura na colheita e rendimento de grãos com umidade corrigida para $13 \%$.

Os dados coletados no experimento foram submetidos à análise de variância, através do teste $\mathrm{F}$, e as médias dos tratamentos foram comparadas aplicando-se o teste de Tukey. Em ambas as análises utilizou-se o nível de 5\% de probabilidade de erro.

\section{RESULTADOS E DISCUSSÃO}

O resultado da análise de variância demonstrou existência de diferenças significativas apenas entre tratamentos relativos ao fator sistemas de pré-semeadura do milho. Para o fator intervalos entre dessecação e semeadura, independente da variável estudada, não ocorreram diferenças estatísticas (tabela 1).

Em relação aos sistemas de présemeadura do milho, é possível constatar que as maiores estaturas de planta, tanto na avaliação realizada aos 20 quanto aos 40 DAE, foram obtidas, independente do herbicida utilizado, nas situações de presença de plantas de aveia-preta, em comparação ao solo descoberto (tabela 2). Entretanto, para massa seca, verificou-se comportamento inverso. Para esta variável, os maiores valores foram obtidos na ausência de resteva de aveia-preta, enquanto os menores valores ocorreram na presença de resteva desta espécie, independente do herbicida utilizado (tabela 2).

Esse comportamento pode decorrer do efeito direto causado pela palha da aveia-preta sobre o crescimento inicial das plântulas de milho. Tal fato decorre da redução da incidência de luz sobre as plantas, resultando no desenvolvimento acentuado da sua parte aérea. O fenômeno, conhecido como estiolamento, foi responsável pela maior estatura e menor massa seca das plantas de milho, o que foi observado na presença de palha dessecada de aveiapreta. Isto pode ser explicado pelo maior gasto energético em expansão celular e não pela divisão celular (incorporação de material orgânico) dessas plantas. Também as alterações na qualidade e quantidade de luz, ocorridas na presença da palha, podem ter influído em um desbalanço hormonal, especialmente nos níveis dos ácidos indolacético e giberélico, envolvidos nos processos de expansão e divisão celular, o que resultou em crescimento diferenciado das plântulas envolvidas.

O estabelecimento e a sobrevivência das plântulas foram afetados pela composição e intensidade da cobertura do solo, sendo a qualidade e a quantidade de luz os principais mecanismos envolvidos nas alterações daquelas variáveis. Desse modo, o crescimento de planta em meio aos resíduos vegetais pode afetar suas características morfológicas. Plântulas de Carduus nutans e de carvalho, por exemplo, que cresceram através de camadas de palha apresentaram-se com hipocótilo maior e estioladas quando comparadas às que cresceram sob menor quantidade ou sem presença de palha (HAMRICK \& LEE, 1987; FACELLI \& PICKETT, 1991). Uma distribuição lateral desigual de luz também pode ter causado o estiolamento de coleóptilos de plantas por promover maior acúmulo de auxinas na região menos iluminada, o que resulta em maior crescimento. De forma semelhante, o ácido giberélico promove elongação de ramos, bem como decréscimo na espessura de ramos e no tamanho de folhas (TAIZ \& ZEIGER, 1991). 
Tabela 1 - Estatura, massa seca de planta e rendimento de grãos de milho semeado sob diferentes sistemas de pré-semeadura, na média de quatro épocas de dessecação da cobertura de aveia-preta, EEA/UFRGS, Eldorado do Sul, RS, 1997/98.

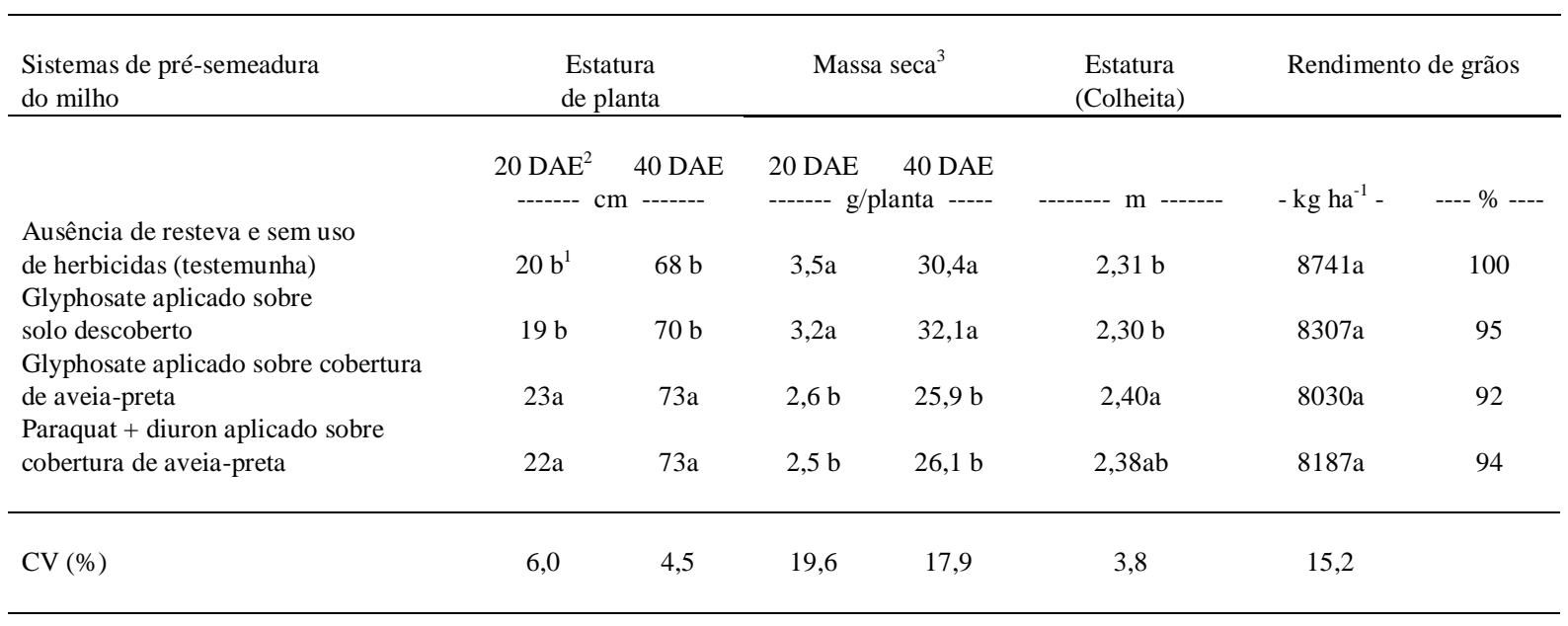

\footnotetext{
${ }^{1}$ Nas colunas, médias seguidas da mesma letra, não diferem significativamente pelo teste de Tukey em nível de $5 \%$ de probabilidade de erro.

${ }^{2}$ Dias após a emergência das plantas de milho.

${ }^{3}$ Da parte aérea das plantas.
}

Ainda, a menor matéria seca obtida nas plantas de milho semeado onde foi aplicado o herbicida glyphosate sobre solo descoberto, não pode ser atribuída ao efeito residual do herbicida, visto que este tratamento não se diferenciou da testemunha (sem herbicida e sem resteva). Sabe-se que este herbicida sofre forte adsorção às partículas de argila e de matéria orgânica, o que o torna praticamente inativo no solo (SPRANKLE et al., 1975; RODRIGUES \& ALMEIDA, 1995).

$O$ efeito inicial ocorrido na estatura de planta permaneceu inalterado na avaliação final de estatura, realizada aos 128 DAE. Contudo, o rendimento de grãos da cultura não apresentou diferenças significativas entre os sistemas utilizados em présemeadura (tabela 2). Também não houve significância estatística, para todas as variáveis avaliadas, entre tratamentos do fator épocas de dessecação da aveia-preta antes da semeadura do milho (tabela 1).

Relato semelhante foi feito por ARGENTA (1998), o qual não obteve diferença estatística para rendimento de grãos de milho cultivado na região de Passo Fundo (RS), com o atraso na época de semeadura da cultura de um para 20 dias após a dessecação da aveia-preta. O autor atribuiu este fato ao alto teor de matéria orgânica contido naquele solo o que, provavelmente, propiciou o suprimento das necessidades iniciais da cultura por nitrogênio através do processo de mineralização basal. Entretanto, no presente experimento, especula-se que a ausência de diferença estatística entre as épocas de dessecação da aveia-preta, antes da semeadura do milho, deveu-se às temperaturas elevadas e à alta precipitação pluvial ocorridas durante o período de condução do trabalho. Tal fato, seguramente, resultou em alterações relevantes nas condições ambientais, que interferiram decisivamente nos processos biológicos (relação $\mathrm{C} / \mathrm{N}$ ) e químicos (alelopatia) ocorrentes no solo.

ROPER (1985) e STOTT et al. (1986) demonstraram que a água e a temperatura do solo exercem efeitos significativos durante os estágios iniciais da decomposição de resíduos vegetais, quando os componentes solúveis em água estão realmente disponíveis. Assim, quando a população microbiana do solo é submetida a algum estresse ambiental, como secamento rápido, esfriamento acentuado do solo ou alguma perturbação mecânica, uma porção da biomassa é morta, sendo rapidamente decomposta pelos microorganismos, liberando nutrientes para as culturas (MARUMOTO, 1984). Também a água participa na relação água/oxigênio, determinando o tipo de metabolismo energético possível de ser utilizado pela população microbiana e, portanto, relacionando-se à velocidade de decomposição dos resíduos. Em condições de capacidade de campo e altas temperatura, os solos apresentam condições ideais para o crescimento das populações microbianas aeróbicas, acelerando a decomposição dos resíduos (FRIES, 1997).

Outro fator que pode ter contribuído para ausência de diferenças entre as épocas de dessecação 
Tabela 2 - Estatura, massa seca de planta e rendimento de grãos de milho semeado sob diferentes intervalos pós-dessecação da cobertura de aveia-preta, na média de quatro sistemas de pré-semeadura do milho, EEA/UFRGS, Eldorado do Sul, RS, $1997 / 98$.

\begin{tabular}{|c|c|c|c|c|c|c|c|}
\hline \multirow[t]{2}{*}{$\begin{array}{l}\text { Intervalos de semeadura } \\
\text { (Após a aplicação dos herbicidas) }\end{array}$} & \multicolumn{2}{|c|}{ Estatura } & \multicolumn{2}{|c|}{ Massa seca $^{1}$} & $\begin{array}{c}\text { Estatura } \\
\text { (Colheita) }\end{array}$ & \multicolumn{2}{|c|}{$\begin{array}{l}\text { Rendimento } \\
\text { de grãos }\end{array}$} \\
\hline & $20 \mathrm{DAE}^{2}$ & $40 \mathrm{DAE}$ & $20 \mathrm{DAE}$ & $40 \mathrm{DAE}$ & & & \\
\hline & ------ c & |------ & ------ g & Inta ----- & ----m ---- & -- $\mathrm{kg} \mathrm{ha}^{-1}--$ & $-\%-$ \\
\hline 13 dias & $21^{\mathrm{ns}}$ & $72^{\mathrm{ns}}$ & $3,2^{\mathrm{ns}}$ & $30,8^{\mathrm{ns}}$ & $2,37^{\mathrm{ns}}$ & $8381^{\text {ns }}$ & 100 \\
\hline 09 dias & 21 & 72 & 3,0 & 27,8 & 2,33 & 7747 & 92 \\
\hline 05 dias & 21 & 70 & 2,8 & 27,3 & 2,34 & 8180 & 98 \\
\hline $01 \mathrm{dia}$ & 20 & 71 & 2,7 & 28,5 & 2,38 & 8549 & 102 \\
\hline $\mathrm{CV}(\%)$ & 6,0 & 4,5 & 19,6 & 17,9 & 3,8 & 15,2 & \\
\hline
\end{tabular}

${ }^{n s}$ F-teste não significativo em nível de $5 \%$ de probabilidade erro.

${ }^{1}$ Da parte aérea das plantas.

${ }^{2}$ Dias após emergência das plantas de milho.

é o provável decréscimo na concentração de aleloquímicos no solo, decorrente de condições de altas temperatura e precipitação pluvial. Isso pode ocorrer tanto pelo aumento na população microbiana (biodegradação), quanto por volatilização e/ou lixiviação dos compostos originados do material vegetal ou da sua degradação.

Segundo VELLOSO \& ROMAN (1993), a concentração de aleloquímicos no solo depende, além do tipo e da taxa de decomposição do resíduo cultural, de outros fatores, como atividade microbiana, temperatura do solo e precipitação pluvial. VIDAL \& BAUMAN (1997) referem que os aleloquímicos interagem no ambiente da mesma forma que os herbicidas e estão sujeitos aos mesmos processos de degradação como decomposição microbiana, fotólise e oxidação, e aos processos de remoção ou transferência, como volatilização e adsorção. Assim, altas temperaturas e chuvas abundantes tendem a acelerar estes processos, ocasionando, consequientemente, o rápido desaparecimento dos fatores de estresse do solo e, ao mesmo tempo, favorecendo o crescimento intenso das plantas.

\section{CONCLUSÕES}

A semeadura do milho em palha de aveiapreta dessecada por herbicidas não-seletivos promove estiolamento no crescimento inicial das plantas, resultando em maior estatura e menor quantidade de massa seca.

A utilização dos herbicidas glyphosate e paraquat+diuron para dessecação de aveia-preta não afeta o crescimento inicial nem o rendimento de grãos do milho semeado em sucessão.
Intervalos de tempo variáveis entre um e 13 dias, entre dessecação da aveia-preta e semeadura do milho, não afetam o desenvolvimento de planta e nem o rendimento de grãos de milho.

\section{REFERÊNCIAS BIBLIOGRÁFICAS}

AITA, C., CERETTA, C.A., THOMAS, A.L., $\boldsymbol{e}$ t $\boldsymbol{a l}$. Espécies de inverno como fonte de nitrogênio para o milho no sistema de cultivo mínimo e feijão em plantio direto. Revista Brasileira de Ciência do Solo, Campinas, v. 18, n. 1, p. 101-108, 1994.

ALMEIDA, F.S. de. A alelopatia e as plantas. Londrina: IAPAR, 1988. $60 \mathrm{p}$.

ARGENTA, G. Manejo do nitrogênio em milho implantado em semeadura direta, em dois ambientes. Porto Alegre-RS, 1998. 101 p. Dissertação (Mestrado em Fitotecnia) - Programa de Pós-graduação em Agronomia, Universidade Federal do Rio Grande do Sul, 1998.

DA ROS, A.O., AITA, C. Efeito de espécies de inverno na cobertura do solo e fornecimento de nitrogênio ao milho em plantio direto. Revista Brasileira de Ciência do Solo, Campinas, v. 20, n. 1, p. 135-140, 1996.

ESPIRITO SANTO, F.R.C. Distribuição de óxidos de Fe em uma catena de solos derivados de granito da região fisiográfica da Depressão Central do Estado do Rio Grande do Sul. Porto Alegre-RS, 1988. 141 p. Dissertação (Mestrado em Solos) - Curso de Pós-graduação em Agronomia, Universidade Federal do Rio Grande do Sul, 1988.

FACELLI, J.M., PICKETT, S.T.A. Plant litter: its dinamics and effects on plant community structure. The Botanical Review, Bronx, v. 57, n. 1, p. 1-32, 1991.

FAY, P.K., DUKE, W.B. An assessment of allelopathic potential in Avena germ plasm. Weed Science, Champaign, v. 25, n. 3, p. 224-228, 1977.

FLECK, N.G., NEVES, R., SILVEIRA, C.A. da. Avaliação do crescimento inicial de milho semeado em restevas de aveia- 
preta e ervilhaca manejadas com e sem herbicida. Pesquisa Agropecuária Gaúcha, Porto Alegre, v. 3, n. 1, p. 35-40, 1997.

FRIES, M.R. Atualização em recomendação de adubação calagem: ênfase em plantio direto. Santa Maria: Pallotti, 1997. Microbiologia e matéria orgânica: recuperação pelo sistema plantio direto: p. 47-75.

HAMRICK, J.L., LEE, J.M. Effects of soil surface topography and litter cover on germination, survival and growth of musk thistle. American Journal of Botany, Colombus, v. 74, n. 3, p. $541-547,1987$.

JACOBI, U.S. Avaliação do potencial alelopático de genótipos de aveia. Porto Alegre-RS, 1997. 165 p. Tese (Doutorado em Fitotecnia) - Programa de Pós-graduação em Agronomia, Universidade Federal do Rio Grande do Sul, 1997.

JENSEN, E.S. Nitrogen immobilization and mineralization during initial decomposition of $15 \mathrm{~N}$-labelled pea and barley residues. Biology Fertility Soils, Berlim, v. 23, n. 3, p. 26-32, 1997.

MARTIN, V.L., McCOY, E.L., DICK, W.U. Allelopathy of crop residues influences corn seed germination and early growth. Agronomy Journal, Madison, v. 82, n. 3, p. 555-560, 1990.

MARUMOTO, T. Mineralization of $\mathrm{C}$ and $\mathrm{N}$ from microbia biomass in paddy soil. Plant and Soil, Dordrecht, v. 76, n. 1, p. $165-173,1984$

PÖTTKER, D., ROMAN, E.S. Efeito de resíduos de culturas e do pousio de inverno sobre a resposta do milho a nitrogênio. Pesquisa Agropecuária Brasileira, Brasília, v. 29, n. 5, p. 763-770, 1994.

RAIMBAUlT, B.A., VYN, T.J., TOLLENAAR, M. Corn response to rye cover crop, tillage methods, and planter options. Agronomy Journal, Madison, v. 85, n. 2, p. 98-106, 1991

RECOMENDAÇÕES técnicas para a cultura do milho no Estado do Rio Grande do Sul. Porto Alegre: FEPAGROEMATER/RS-FECOTRIGO, 1997. 140 p. Boletim Técnico, 4.
RODRIGUES, B.N., ALMEIDA, F.S. de. Guia de Herbicidas: contribuição para o uso adequado em plantio direto e convencional. 3. ed. Londrina: IAPAR, 1995. 482 p.

ROPER, M.M. Straw decomposition and nitrogenase activity $\left(\mathrm{C}_{2} \mathrm{H}_{2}\right.$ reduction): Effects of soil moisture and temperature. Soil Biology Biochemistry, Oxford, v. 17, n. 1, p. 65-71, 1985.

RUEDELL, J. Plantio direto na região de Cruz Alta. Cruz Alta: Convênio FUNDACEP/BASF, FUNDACEP/FECOTRIGO 1995. $134 \mathrm{p}$.

SÁ, J.C.M. de. Plantio direto no Brasil. Passo Fundo: Aldeia Norte, EMBRAPA-CNPT, FECOTRIGO, Fundação ABC 1993. Manejo de fertilidade do solo no sistema plantio direto: p. 41-47.

SPRANKLE, P., MEGGITT, W.F., PENNER, D. Rapid inactivation of glyphosate in the soil. Weed Science, Champaign, v. 23, n. 3, p. 224-228, 1975.

STOTT, D.E., ELLIOTT, L.F., PAPENDICK, R.I. et al. Low temperature or low water effects on microbial decomposition of wheat residue. Soil Science Society America Journal, Madison, v. 18, n. 3, p. 577-582, 1986.

TAIZ, L., ZEIGER, E. Plant Physiology. Redwood City: Benjamin/Cummings, 1991. 565 p.

TEIXEIRA, L.A.J., TESTA, V.M., MIELNICZUK, J. Nitrogênio do solo, nutrição e rendimento de milho afetados por sistemas de cultura. Revista Brasileira de Ciência do Solo, Campinas, v. 18 , n. 2 , p. $207-214,1994$

VELlOSO, J.A.R.O., ROMAN, E.S. Plantio direto no Brasil. Passo Fundo: Aldeia Norte, EMBRAPA-CNPT, FECOTRIGO, Fundação ABC, 1993. Controle cultural, coberturas mortas e alelopatia em sistemas conservacionistas: p. 77-84.

VICTORIA, R.L., PICCOLO, M.C., VARGAS, A.A.T Microbiologia do Solo. Campinas, Sociedade Brasileira de Ciência do Solo, 1992. O ciclo do nitrogênio: p. 105-120.

VIDAL, R.A., BAUMAN, T.T. Fate of allelochemicals in the soil. Ciência Rural, Santa Maria, v. 27, n. 2, p. 351-357, 1997.

Ciência Rural, v. 29, n. 4, 1999. 